\title{
Hyperbaric Oxygen Treatment in a Diabetic Rat Model Is Associated with a Decrease in Blood Glucose, Regression of Organ Damage and Improvement in Wound Healing
}

\author{
Sulistiana Prabowo', Maria Nataatmadja ${ }^{2}$, Janto Poernomo Hadi', Irmawati Dikman' ${ }^{1}$ \\ Fitri Handajani1, Sihning E. J. Tehupuring1, Iswahyudi Soetarso1, \\ Mohammad Guritno Suryokusumo', Aulanni'am Aulanni'am³, Anita Herawati3 , \\ Malcolm West ${ }^{2}$ \\ ${ }^{1}$ Faculty of Medicine, Hang Tuah University, Surabaya, Indonesia \\ ${ }^{2}$ Cardiovascular Research Group, Prince Charles Hospital, School of Medicine, University of Queensland, \\ Brisbane, Australia \\ ${ }^{3}$ Biochemistry Laboratory, Faculty of Sciences, Brawijaya University, Malang, Indonesia \\ Email: $\underline{\text { m.nataatmadja@uq.edu.au }}$
}

Received 6 June 2014; revised 23 July 2014; accepted 4 August 2014

Copyright (C) 2014 by authors and Scientific Research Publishing Inc.

This work is licensed under the Creative Commons Attribution International License (CC BY).

http://creativecommons.org/licenses/by/4.0/

(c) (i) Open Access

\section{Abstract}

Diabetes leads to widespread complications including pancreatic $\beta$-cell damage, nephropathy and impaired wound healing. Hyperbaric oxygen therapy (HBOT) has been shown to improve wound healing through induction of stem cell recruitment and the potential to inhibit progression of diabetic complications. We aimed to determine the efficacy of HBOT in wound healing and organ preservation in a diabetic rat model. Diabetes was induced in male Wistar rats ( $n=10$ /group) using streptozotocin $(20 \mathrm{mg} / \mathrm{kg} \mathrm{sc})$ daily for 3 days. A wound was inflicted on the skin over the back and the rats were given HBOT (2.3 ATA for $1 \mathrm{~h} /$ day) for $1,3,5,7$ or 10 days or were not treated. Blood glucose, pancreatic $\beta$-cell damage, diabetic nephropathy and wound healing progression were assessed. Diabetic rats not treated with HBOT had significantly higher blood glucose levels compared to controls $(26.7 \pm 3.3 \mathrm{mmol} / \mathrm{L}$ vs. $5.8 \pm 0.4 \mathrm{mmol} / \mathrm{L} ; \mathrm{P} \leq 0.05)$. This was associated with significant increase in the percentage of $\beta$-cell damage $(72 \% \pm 9 \%$ vs. $10 \% \pm 2 \% ; P \leq 0.05)$ and diabetic nephropathy. HBOT for 3 days and longer in diabetic rats reduced hyperglycemia to control levels. Pancreatic $\beta$-cell damage was negligible in rats treated with HBOT for 5 days and longer while diabetic nephropathy was diminished in animals treated for 10 days. Similarly HBOT induced wound healing and accelerated epithelial closure from 5 days of HBOT. In summary, our findings show the efficacy of HBOT in this diabetic rat model. There was significant reduction of hyperglycemia and inhibition of diabetic complications in the form of preservation of pancreatic 
and kidney structure and accelerated wound healing.

Keywords

Diabetes, Hyperbaric Therapy, Wound, Pancreas, Kidney

\section{Introduction}

Diabetes affects people worldwide and is currently viewed as the major epidemic of this century. The incidence of new diabetics has been reported to be increased by $50 \%$ over the last 10 years [1] [2]. An estimated $7.7 \%$ of adults in developed countries have type 2 diabetes [3]. By 2030, it is predicted that the number of diabetes sufferers will increase by $20 \%$ in developed countries and by $70 \%$ in developing countries [4] [5]. It is a major independent risk factor for cardiovascular disease with up to 10 fold increased risk of cardiovascular events compared to age-matched non-diabetic patients. However, the cause of diabetes is still not known [6] [7]. The presence of hyperglycemia and associated vascular dysfunction in diabetes has multiple confounding effects manifested in various diabetic complications. Vascular defects in diabetes are known to be associated with endothelial dysfunction and reactive oxygen species (ROS) have been implicated in the pathogenesis of diabetes mellitus [8] [9]. Persistent hyperglycemia induces ROS production which subsequently alters the regulation of eNOS, von Willebrand factor and nitric oxide production [10]-[13]. The condition affects stem cell function contributing to poor wound healing and low grade chronic inflammation. This is ultimately manifested in multiple diabetic complications including pancreatic $\beta$-cell damage, retinopathy, neuropathy, nephropathy, atherosclerosis and myocardial infarction [12]. Diabetic foot ulcers are estimated to occur in $15 \%$ of all patients with diabetes and are the leading cause of hospital admissions for people with diabetes in developed countries [14]. Foot ulcers are a major diabetic associated morbidity often leading to a poor quality of life and precede most diabetes related lower leg amputations [4].

Type 1 diabetes mellitus is characterized by the autoimmune destruction of the insulin-expressing pancreatic $\beta$-cells resulting in dependency on exogenous insulin to control blood glucose levels. Sufferers are prone to diabetic complication due partly from physiological fluctuations in insulin secretion and higher than normal glucose levels [15]. Previous studies have indicated the importance of preservation of functional $\beta$-cells. The use of exogenous cell replacement such as progenitor cell transplantation has been studied [16] [17]. Based on current limited knowledge of progenitor cell differentiation and maturation however, this is a complicated technique with unpredictable outcomes. Preservation of existing functional $\beta$-cells is more favourable and treatment strategies should be directed towards endogenous regeneration where possible.

Wound hypoxia is typically found following disruption of the microcirculation at the time of an injury. Oxygen tension of less than $3 \mathrm{mmHg}$ is commonly found within the wound in comparison to oxygen tension of approximately $20 \mathrm{mmHg}$ in the peri-wound area [18]. Wound hypoxia is necessary in early wound phase for leukocyte adherence and induction of neovascularization and collagen formation. The persistence of hypoxia in chronic wound conditions however blunts polymorphonuclear and antibacterial activity as well as collagen synthesis and neovascularization [19] [20]. A hypoxic environment also decreases epithelialization due to reduced epithelial growth factor activity and greatly reduced macrophage bacterial phagocyte activity [20]. An oxygen environment of $40 \mathrm{mmHg}$ is needed to sustain fibroblast activity that will lead to collagen deposition in wound repair [18].

Hyperbaric oxygen therapy (HBOT) is a treatment modality where subjects breathe $100 \% \mathrm{O}_{2}$ while exposed to increased atmospheric pressure (2 - 3 atmospheres absolute; 2 - 3 ATA). Treatment is usually given for 1 to 2 $\mathrm{h}$ daily for various periods of time. It is well accepted that breathing greater than 1 ATA of $\mathrm{O}_{2}$ increase the production of ROS [21]. HBOT is used to treat refractory diabetic wounds which are associated with decreased growth factor production, chronic inflammation, fibrosis and impaired keratinocyte function [22]. HBOT has been shown to induce wound healing and reduced the risk of major amputations in human subjects [23]. The mechanism of action is still not clear but its efficacy is associated with a combination of systemic induced factors and local factors in the wound margin. HBOT induces local neovascularisation and vasculogenesis through local angiogenesis and enhancement of endothelial progenitor cell mobilisation and homing in the absence of circulating leucocyte elevation [17] [24]-[26]. The efficacy of HBOT in diabetic complications such as retinopathy, neuropathy and nephropathy has been reported. The effects may be related to reduced neutrophil $\beta$ inte- 
grin adhesion and thus temporary inhibition of circulating neutrophils to adhere to target tissues without reducing neutrophil viability and functions such as degranulation, phagocytosis, and oxidative burst in response to chemoattractants [21].

In this study, we investigated the capacity of HBOT to inhibit the progression of diabetic complications including organ preservation and wound healing. It is known that hyperglycemia in diabetes induces 1) chronic inflammation associated with organ damage including destruction of the insulin-expressing pancreatic $\beta$-cells and nephropathy and 2) endothelial progenitor cell dysfunction associated with abnormal angiogenesis, vasculogenesis and impaired wound healing. We hypothesised that HBOT inhibits hyperglycemia with associated inhibition of diabetic complications including damage to pancreatic $\beta$-cells and nephropathy, endothelial cell and microvessel function and poor wound healing. We have used our established diabetic Wistar rat model where we are able to induce hyperglycemia without instigating irreversible damage to functional pancreatic $\beta$-cells thus enabling us to conduct a regeneration study.

\section{Methods}

\subsection{Preparation of Animals for the Study}

Wistar diabetic rats (male, $250 \mathrm{~g} \pm 30 \mathrm{~g}$ ) used for the study were purchased from Brawijaya University Animal Resource Centre, Malang, Indonesia. They were housed at $25^{\circ} \mathrm{C} \pm 2^{\circ} \mathrm{C}$ with daily 12 hour light on and off cycle, fed standard chow diet and water ad libitum. The study was approved and conducted in accordance to the local Institution guidelines for animal research at Brawijaya University, Malang, Indonesia. The experiment protocol for animal was in accordance with the standard animal welfare guideline. Diabetes was induced by injection of streptozotocin (20 mg/kg/day) for 3 days. The model has been established and fully tested in our centre so as to induce diabetes without causing irreversible damage to the pancreas. Two weeks after diabetic induction the level of glycemia was measured and animals with blood glucose level of $11.1-22.2 \mathrm{mmol} / \mathrm{L}$ were selected for the study [12]. They were divided into 7 groups: non-treated non-diabetic rats (control rats), non-treated diabetic rats and 5 groups of HBOT diabetic rats ( $n=10$ /group).

Three weeks after diabetic induction all groups of animals were anesthetised with an intramuscular injection of ketamine (20 mg/kg). The dorsum were clipped free of hair and a full thickness wound incision (2 cm long) was made along the spine at the upper back of the rats following techniques previously published [27].

\subsection{HBOT}

HBOT of 2.4ATA was given for 60 minutes once per day for periods of 1, 3, 5, 7 or 10 days post wounding to the diabetic treated groups in the small animal hyperbaric chamber at the same time in the morning to exclude the possible effect on the circadian rhythm. The Lakesla Dr. Ramelan Naval Hospital, Surabaya, Indonesia has fully operational hyperbaric facilities for studies of human and small animal models. Figure 1 shows the equipment used for animal studies.

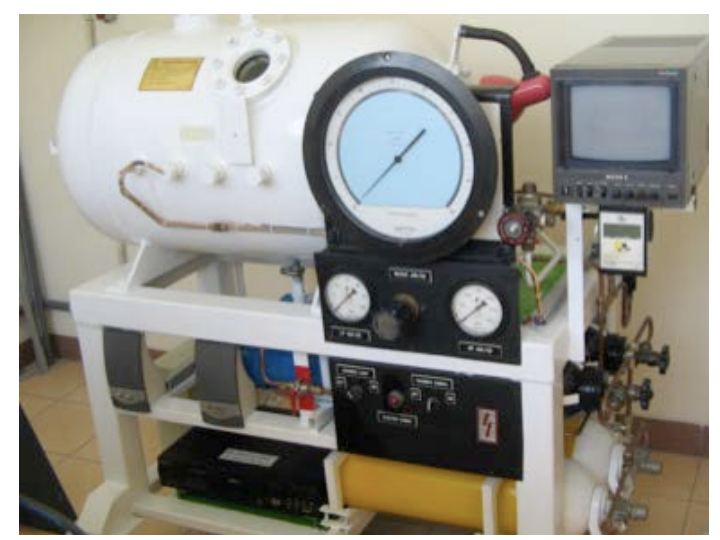

Figure 1. Hyperbaric chamber in Lakesla Dr. Ramelan Naval Hospital. This equipment is routinely used for small animal experiments. 


\subsection{Blood and Tissue Harvest}

At the end of the experiment the animals were sacrificed by overdose of intramuscular injection of ketamine $(100 \mathrm{mg} / \mathrm{kg})$. Blood was collected in EDTA coated tubes. Blood glucose levels were measured using standard procedures at the end of the experiment in each group. The pancreas and kidney were removed and fixed in $10 \%$ buffered formalin for histological study. Histological samples were processed and embedded in paraffin, cut at 5 $\mu \mathrm{m}$ thickness and stained in hematoxylin and eosin ( $\mathrm{H} \& \mathrm{E}$ ). The severity of pancreatic damage was assessed based on the degree of insulitis. Scoring was made based on the degree of islet of Langerhans-specific inflammation as reported previously [28]. Higher number of inflammatory cell infiltration indicates worse pancreatic damage. Diabetic nephropathy was assessed morphologically using H \& E staining. Scoring was based on the classification of diabetic nephropathy using the presence (score of 1 ) or absence (score of 0 ) of each of 3 scoring categories, i.e. glomerulosclerosis, tubular atrophy [29] and inflammatory cell infiltration. An average score for each animal was determined by adding together the individual category score and the results were averaged for each group. Scores were then compared between groups.

\subsection{Skin Wound Harvest}

Photographs were taken of the wound area $3 \mathrm{~h}$ post wounding and prior to sacrifice at the end of each experiment. The entire wound area including the skin and tissue surrounding the wound was dissected and fixed in $10 \%$ buffered formalin, processed and embedded in paraffin. The histological sections were cut at $5 \mu \mathrm{m}$ thickness and stained with H \& E. Histological assessment was carried out on sections derived from the widest part of the wound following the published methods of wound skin harvest [30]. Wound closure was analysed based on the macroscopic observation of skin closure and histological evidence of epidermal closure.

\subsection{Statistical Analysis}

Comparisons between groups are presented as mean \pm standard deviation (SD). Statistical significance was determined using unpaired $t$-test analysis of GraphPad Prism version 6.04 statistical program with a $\mathrm{P}$ value of at least $<0.05$ considered significant.

\section{Results}

\subsection{Blood Glucose Level Measurement}

Significant increase of blood glucose level was found in non-treated diabetic rats compared to non-treated non-diabetic rats $(26.7 \pm 3.3 \mathrm{mmol} / \mathrm{L}$ vs. $5.8 \pm 0.4 \mathrm{mmol} / \mathrm{L} ; \mathrm{P} \leq 0.05)$.

HBOT reduced the blood glucose level of diabetic rats in a time dependent manner. No significant difference in the blood glucose level was found in HBOT diabetic rats from Day 3 onwards compared to control nontreated non-diabetic rats (Figure 2).

\subsection{Pancreatic $\beta$-Cell Damage}

Histological study showed the presence insulitis associated with significant loss in the number of pancreatic $\beta$-cells in non-treated diabetic rats compared to non-treated non diabetic rats and increase inflammatory cell infiltrate. HBOT resulted in the increase number of pancreatic $\beta$-cell content and reduction of inflammatory infiltrate in time dependent manner (Figure 3). Quantitative analysis showed significant increase in the number of inflammatory cells in non-treated diabetic rats compared to non-treated non-diabetic rats (72 \pm 9 vs. $10 \pm 2$; mean $\pm \mathrm{SD}, \mathrm{P} \leq 0.05$ ). HBOT reduced the number of inflammatory cell infiltrate in a time dependent manner. HBOT diabetic rats treated for 5 days onwards showed statistically significant increase in pancreas regeneration where the number of inflammatory cell infiltrate was significantly reduced and no difference compared to nontreated non-diabetic rats (Figure 4).

\subsection{Diabetic Nephropathy}

Based on our scoring system there was nephropathy in non-treated diabetic rats in two markers with glomerulosclerosis and tubular atrophy. We also found substantial inflammatory cell infiltration in the interstitial tissue 


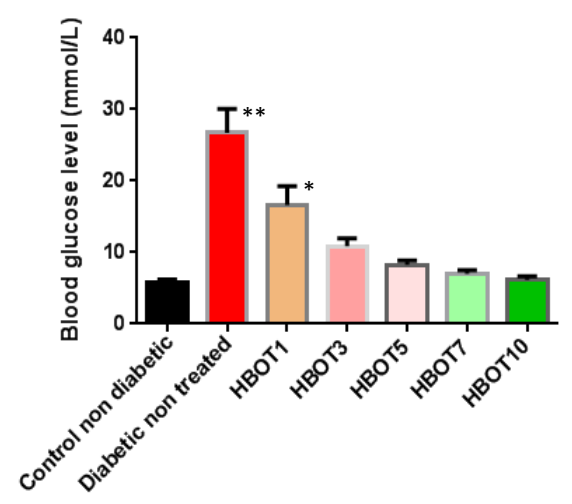

\begin{tabular}{|c|c|c|c|c|c|c|c|}
\hline Group & Control & Diabetic & HBOT-1 & HBOT-3 & HBOT-5 & HBOT-7 & HBOT-10 \\
\hline $\begin{array}{c}\text { Mean } \pm \text { DD } \\
\text { (mmol/L) }\end{array}$ & $5.8 \pm 0.4$ & $26.7 \pm 3.3^{* *}$ & $16.6 \pm 2.7 *$ & $10.9 \pm 1.1$ & $8.3 \pm 0.6$ & $7.0 \pm 0.5$ & $6.2 \pm 0.5$ \\
\hline
\end{tabular}

Figure 2. Blood glucose levels of control non-diabetic rats and diabetic nonreated and diabetic HBOT groups $(\mathrm{mmol} / \mathrm{L}) ;{ }^{*} \mathrm{P}<0.05,{ }^{* *} \mathrm{P}<0.01$.

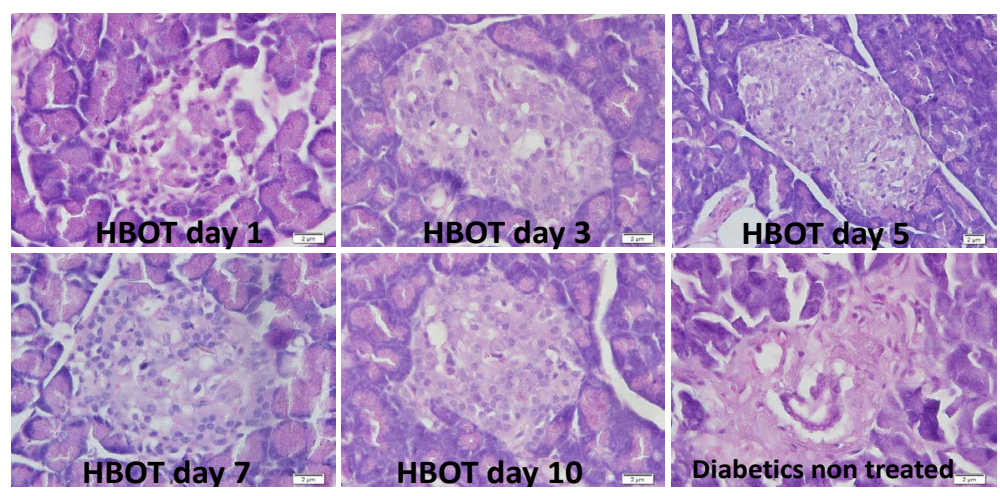

Figure 3. Insulitis identification associated with pancreatic $\beta$-cell loss and inflammatory cell infiltration in non-treated diabetic rat and diabetic rat with HBOT for 1, 3, 5, 7 or 10 days. Hematoxylin \& Eosin staining; magnification $400 \times$.

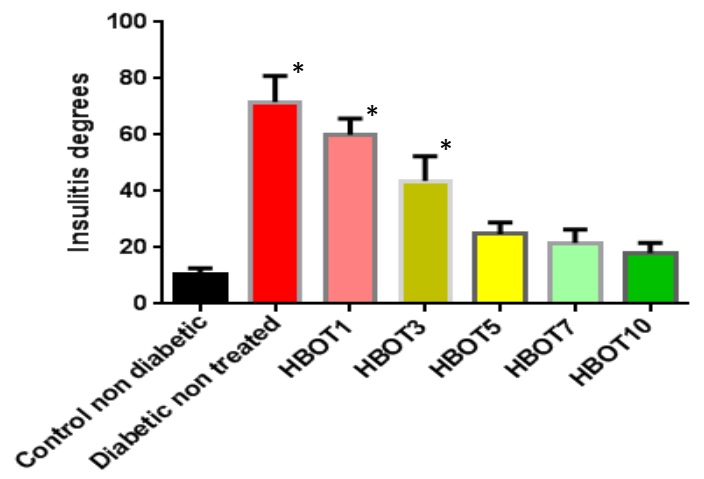

\begin{tabular}{|c|c|c|c|c|c|c|c|}
\hline Group & Control & Diabetic & HBOT-1 & HBOT-3 & HBOT-5 & HBOT-7 & HBOT-10 \\
\hline Mean \pm SD & $10 \pm 2 \%$ & $72 \pm 9 \% *$ & $60 \pm 6 \% *$ & $44 \pm 9 \% *$ & $25 \pm 4 \%$ & $22 \pm 5 \%$ & $18 \pm 4 \%$ \\
\hline
\end{tabular}

Figure 4. Analysis of insulitis degrees. The number of inflammatory cell infiltration in the islets of Langerhans resembled insulitis severity. Comparison was made between control non-diabetic rats vs. diabetic non-treated and diabetic HBOT groups; ${ }^{*} \mathrm{P}<0.05$. 
while non-treated non-diabetic control rats were negative of these markers. HBOT reduced the severity of diabetic nephropathy and animals treated with HBOT for 10 days showed complete recovery of renal histology with zero scores for each of the 3 markers of diabetic nephropathy and absence of inflammatory cell infiltration (Figure 5).

\subsection{Wound Healing}

Classification of wound healing stages was done based on the previous published report of wound healing sequence of events [27]. Macroscopic views of the skin incision showed significant improvement of wound closure at 10 days following HBOT compared to the non-treated diabetic rats (Figure 6). Histological assessment of the wound incision again showed significant improvement in the degree of epithelial closure with HBOT. Diabetic rats treated for 5 days with HBOT onwards showed complete closure of the epithelial flap compared to the diabetic non-treated rats where at the end of the experiment (Day 10) the degree of epithelial closure were similar to findings following HBOT at Day 3 (Figure 7).

\section{Discussion}

Despite extensive studies the cause of diabetes remains elusive. Sedentary life style in combination with modern dietary content increases the prevalence of diabetes. HBOT has been used worldwide to treat decompression sickness as well as to assist in the problem of wound healing in both diabetic and non-diabetic conditions. The

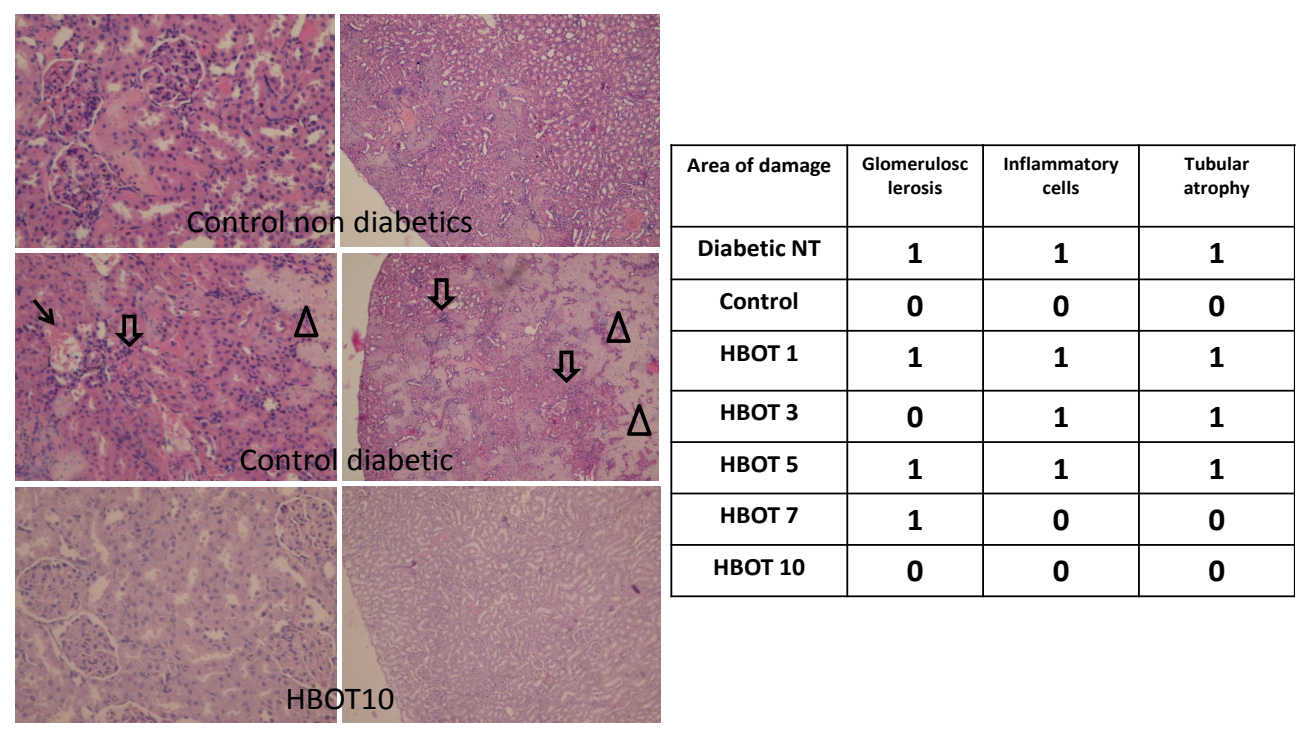

Figure 5. Diabetic nephropathy scores based on glomerulosclerosis (arrow), tubular atrophy (arrowhead) and inflammatory cell infiltration (block arrow). Comparison was made between non-diabetic rats and non-treated diabetic rats and HBOT diabetic groups. Magnification 200× (left panel) and $40 \times$ (right panel).

\section{Wound closure - macroscopic view of skin}

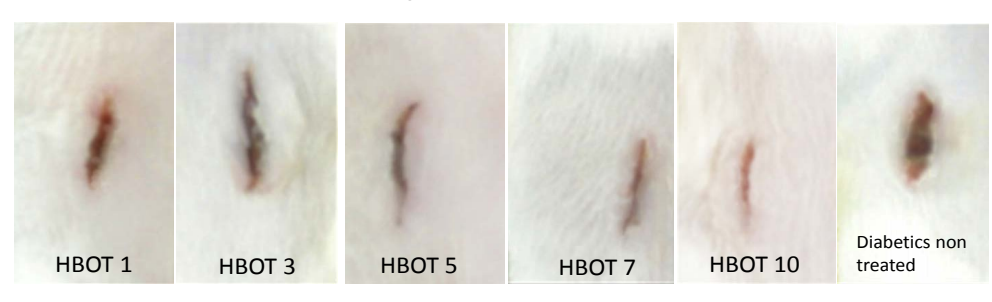

Figure 6. Gross images of wound injury. Non-treated diabetic rat showed persistent wound gap whereas the HBOT diabetic rats showed improved wound healing. 


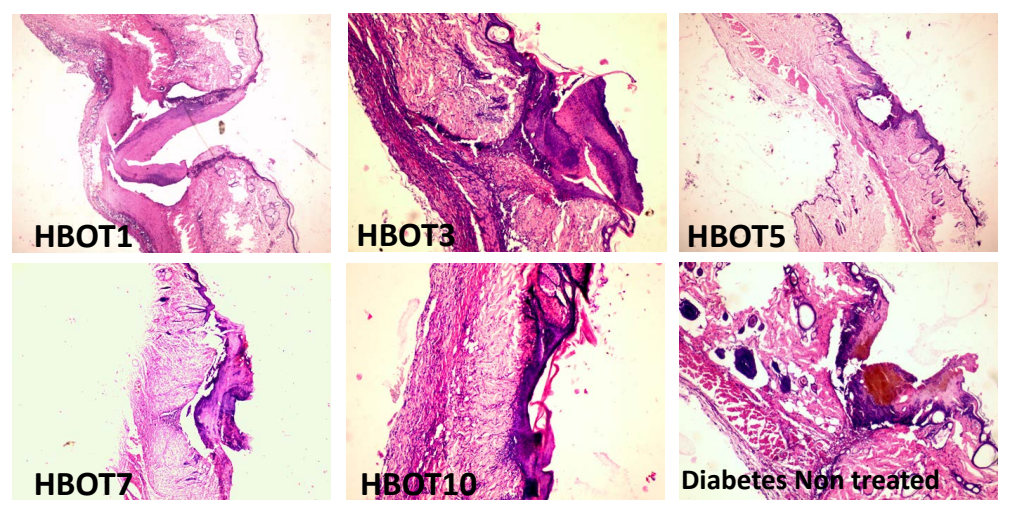

Figure 7. Histological view of wound closures. Non-treated diabetic rat showed persistent wound gap whereas the HBOT diabetic rats showed improved wound closure. Hematoxylin \& Eosin staining; magnification 40×.

treatment has been shown to have a favourable impact on accelerated wound healing. Despite the highly successful effects in treating various conditions the underlying mechanism of action of HBOT is still not clear and further studies are needed.

The commonly investigated rat models of diabetes have beenWistar and Sprague Dawley rat strains induced by a single injection of streptozotocin (40 - $60 \mathrm{mg} / \mathrm{kg}$ ) [12] [31]. In our previous experience, however, diabetes induction by single higher doses of streptozotocin in these animal models is often associated with the occurrence of complete and irreversible damage of the pancreas. We have established a modified diabetic rat model using the Wistar rat strain. We induced diabetes by multiple low dose injection of stretozotocin $(20 \mathrm{mg} / \mathrm{kg} / \mathrm{day})$ for 3 days. We have noted that using this modified technique we are able to consistently induce diabetes. In addition, the presence of diabetes was not associated with irreversible damage of the pancreas. We believe our model more closely resembles human diabetes in which the insulin producing $\beta$-cells in the pancreas still have some degree of function. The model is thus more appropriate for studies to determine the possible regeneration of the pancreas and $\beta$-cell function when diabetes is reversed.

In the present study, we have shown that HBOT suppresses hyperglycemia in diabetic rats. The reduction of blood sugar level was correlated with reduction in the percentage of $\beta$-cell damage in the pancreas. Previous studies have shown that clinically recommended HBOT significantly enhanced oxidative stress and induced ROS production and apoptosis in pancreatic $\beta$-cells in diabetic rats [12]. In contrast our findings show decreased degree of the $\beta$-cell damage in the pancreas. The difference may be due to different methods of assessment of cell loss. An apoptotic marker was not used in the present studies while in other studies HBOT was used for longer time periods. Our findings are very promising as they show lowering of blood sugar level with HBOT is not just a temporary effect but potentially can permanently reverse diabetes if regeneration of $\beta$-cells can be fully induced and function fully restored. Further long term study is needed to determine whether the regeneration of the $\beta$-cells observed after HBOT in this study is maintained long term. More importantly further long term study will determine whether the reduction of the percentage of pancreatic $\beta$-cells damage observed in this study is associated with recovery of insulin producing function in these cells and maintenance of stable blood sugar levels.

We have also shown that non-treated diabetic rats develop diabetic nephropathy and HBOT is associated with reduction in severity of nephropathy. Animals treated with HBOT for 10 days showed no difference in histological renal markers of nephropathy compared to the non-diabetic rat group. This further confirms previous investigators' findings that HBOT inhibits or at least slows down the progression of diabetic complications. In this study, we showed that HBOT reduced blood sugar level. This is associated with the regeneration of kidney structure and reduced severity of the nephropathy observed histologically. Similar to our findings in the pancreas further long term study is needed to determine whether the inhibition of nephropathy observed in this study after HBOT can be maintained and more importantly whether kidney function can be restored.

Accelerated wound healing was also demonstrated in our diabetic rats after HBOT. This finding confirms previous investigators' findings suggesting efficacy of HBOT in wound healing [32]-[36]. Gross wound healing observations showed significant improvement of wound closure in diabetic rats treated with HBOT compared to 
non-treated diabetic rats. Our histological study supports the macroscopic observations of wound healing showing the degree of epithelial closure in non-treated diabetic rats on Day 10 is similar to the degree of epithelial closure at Day 3 of HBOT. This significant improvement of wound healing in this model can be attributed to the reduction of hyperglycemia after HBOT. It is likely that reduction of blood sugar level is associated with normalisation of vasculogenesis and progenitor endothelial cell function. Normalisation of microvascular function is vital for wound healing induction and most likely is the cause of accelerated wound healing in the diabetic rat model receiving HBOT.

In conclusion, our study has shown efficacy of HBOT in our diabetic animal model. Reduction of blood sugar level after HBOT is associated with regeneration of pancreatic $\beta$-cells and improvement in diabetic nephropathy. The frequency and dose of HBOT still needs to be determined to achieve the maximum efficacy and lowest side effects. Further study is needed to determine the long term effect of HBOT and whether organ regeneration found in the pancreas and kidney is associated with the recovery of organ function. Finally long term study will be define the role of HBOT in diabetes and whether additional treatment will be required to maintain suppression of blood sugar levels and normal organ function recovery.

\section{References}

[1] Danaei, G., et al. (2011) National, Regional, and Global Trends in Fasting Plasma Glucose and Diabetes Prevalence since 1980: Systematic Analysis of Health Examination Surveys and Epidemiological Studies with 370 Country-Years and 2.7 Million Participants. Lancet, 378, 31-40. http://dx.doi.org/10.1016/S0140-6736(11)60679-X

[2] Onkamo, P., et al. (1999) Worldwide Increase in Incidence of Type I Diabetes-The Analysis of the Data on Published Incidence Trends. Diabetologia, 42, 1395-1403. http://dx.doi.org/10.1007/s001250051309

[3] Gray, S.P. and Jandeleit-Dahm, K. (2014) The Pathobiology of Diabetic Vascular Complications-Cardiovascular and Kidney Disease. Journal of Molecular Medicine, 92, 441-452. http://dx.doi.org/10.1007/s00109-014-1146-1

[4] Brem, H. and Tomic-Canic, M. (2007) Cellular and Molecular Basis of Wound Healing in Diabetes. Journal of Clinical Investigation, 117, 1219-1222. http://dx.doi.org/10.1172/JCI32169

[5] Shaw, J.E., Sicree, R.A. and Zimmet, P.Z. (2010) Global Estimates of the Prevalence of Diabetes for 2010 and 2030. Diabetes Research and Clinical Practice, 87, 4-14. http://dx.doi.org/10.1016/j.diabres.2009.10.007

[6] Cooper, M.E., et al. (2001) Mechanisms of Diabetic Vasculopathy: An Overview. American Journal of Hypertension, 14, 475-486. http://dx.doi.org/10.1016/S0895-7061(00)01323-6

[7] Rahman, S., et al. (2007) Diabetes-Associated Macrovasculopathy: Pathophysiology and Pathogenesis. Diabetes, Obesity and Metabolism, 9, 767-780. http://dx.doi.org/10.1111/j.1463-1326.2006.00655.x

[8] Brownlee, M. (2001) Biochemistry and Molecular Cell Biology of Diabetic Complications. Nature, 414, 813-820. http://dx.doi.org/10.1038/414813a

[9] Kowluru, R.A. and Chan, P.S. (2007) Oxidative Stress and Diabetic Retinopathy. Experimental Diabetes Research, 2007, 43603.

[10] Buras, J.A., et al. (2000) Hyperbaric Oxygen Downregulates ICAM-1 Expression Induced by Hypoxia and Hypoglycemia: The Role of NOS. American Journal of Physiology—Cell Physiology, 278, C292-C302.

[11] Hink, J., Thom, S.R., Simonsen, U., Rubin, I. and Jansen, E. (2006) Vascular Reactivity and Endothelial NOS Activity in Rat Thoracic Aorta during and after Hyperbaric Oxygen Exposure. American Journal of Physiology-Heart and Circulatory Physiology, 291, H1988-H1998. http://dx.doi.org/10.1152/ajpheart.00145.2006

[12] Matsunami, T., Sato, Y., Hasegawa, Y., Ariga, S., Kashimura, H., Sato, T. and Yukawa, M. (2011) Enhancement of Reactive Oxygen Species and Induction of Apoptosis in Streptozotocin-Induced Diabetic Rats under Hyperbaric Oxygen Exposure. International Journal of Clinical and Experimental Pathology, 4, 255-266.

[13] Wolff, S.P., Jiang, Z.Y. and Hunt, J.V. (1991) Protein Glycation and Oxidative Stress in Diabetes Mellitus and Ageing. Free Radical Biology and Medicine, 10, 339-352. http://dx.doi.org/10.1016/0891-5849(91)90040-A

[14] Reiber, G.E., Vileikyte, L., Boyko, E.J., del Aguila, M., Smith, D.G., Lavery, L.A. and Boulton, A.J. (1999) Causal Pathways for Incident Lower-Extremity Ulcers in Patients with Diabetes from Two Settings. Diabetes Care, 22, 157162. http://dx.doi.org/10.2337/diacare.22.1.157

[15] Aguayo-Mazzucato, C. and Bonner-Weir, S. (2010) Stem Cell Therapy for Type 1 Diabetes Mellitus. Nature Reviews Endocrinology, 6, 139-148. http://dx.doi.org/10.1038/nrendo.2009.274

[16] Couri, C.E. and Voltarelli, J.C. (2008) Potential Role of Stem Cell Therapy in Type 1 Diabetes Mellitus. Arquivos Brasileiros de Endocrinologia \& Metabologia, 52, 407-415. http://dx.doi.org/10.1590/S0004-27302008000200029

[17] Liu, Z.J. and Velazquez, O.C. (2008) Hyperoxia, Endothelial Progenitor Cell Mobilization, and Diabetic Wound Heal- 
ing. Antioxidants \& Redox Signaling, 10, 1869-1882. http://dx.doi.org/10.1089/ars.2008.2121

[18] Broussard, C.L. (2004) Hyperbaric Oxygenation and Wound Healing. Journal of Vascular Nursing, 22, 42-48. http://dx.doi.org/10.1016/j.jvn.2004.03.001

[19] Hunt, T.K., Burke, J., Barbul, A. and Gimbel, M.L. (1999) Wound Healing. Science, 284, 1775.

[20] Boykin, J.V. (2002) How Hyperbaric Oxygen Therapy Helps Heal Chronic Wounds. Nursing, 32, 24. http://dx.doi.org/10.1097/00152193-200206000-00017

[21] Thom, S.R. (2011) Hyperbaric Oxygen: Its Mechanisms and Efficacy. Plastic and Reconstructive Surgery, 127, 131S141S. http://dx.doi.org/10.1097/PRS.0b013e3181fbe2bf

[22] Falanga, V. (2005) Wound Healing and Its Impairment in the Diabetic Foot. Lancet, 366, 1736-1743. http://dx.doi.org/10.1016/S0140-6736(05)67700-8

[23] Duzgun, A.P., Satır, H.Z., Ozozan, O., Saylam, B., Kulah, B. and Coskun, F. (2008) Effect of Hyperbaric Oxygen Therapy on Healing of Diabetic Foot Ulcers. The Journal of Foot and Ankle Surgery: Official Publication of the American College of Foot and Ankle Surgeons, 47, 515-519. http://dx.doi.org/10.1053/j.jfas.2008.08.002

[24] Gallagher, K.A., Liu, Z.J., Xiao, M., Chen, H.Y., Goldstein, L.J., Buerk, D.G., Nedeau, A., Thom, S.R. and Velazquez, O.C. (2007) Diabetic Impairments in NO-Mediated Endothelial Progenitor Cell Mobilization and Homing Are Reversed by Hyperoxia and SDF-1 $\alpha$. Journal of Clinical Investigation, 117, 1249-1259. http://dx.doi.org/10.1172/JCI29710

[25] Velazquez, O.C. (2007) Angiogenesis and Vasculogenesis: Inducing the Growth of New Blood Vessels and Wound Healing by Stimulation of Bone Marrow-Derived Progenitor Cell Mobilization and Homing. Journal of Vascular Surgery: Official Publication, the Society for Vascular Surgery [and] International Society for Cardiovascular Surgery, North American Chapter, 45, A39-A47.

[26] Thom, S.R., Milovanova, T.N., Yang, M., Bhopale, V.M., Sorokina, E.M., Uzun, G., Malay, D.S., Troiano, M.A., Hardy, K.R., Lambert, D.S., Logue, C.J. and Margolis, D.J. (2011) Vasculogenic Stem Cell Mobilization and Wound Recruitment in Diabetic Patients: Increased Cell Number and Intracellular Regulatory Protein Content Associated with Hyperbaric Oxygen Therapy. Wound Repair and Regeneration: Official Publication of the Wound Healing Society [and] the European Tissue Repair Society, 19, 149-161.

[27] Braiman-Wiksman, L., Solomonik, I., Spira, R. and Tennenbaum, T. (2007) Novel Insights into Wound Healing Sequence of Events. Toxicologic Pathology, 35, 767-779. http://dx.doi.org/10.1080/01926230701584189

[28] In’t Veld, P. (2011) Insulitis in Human Type 1 Diabetes: The Quest for an Elusive Lesion. Islets, 3, 131-138. http://dx.doi.org/10.4161/isl.3.4.15728

[29] Tervaert, T.W., Mooyaart, A.L., Amann, K., Cohen, A.H., Cook, H.T., Drachenberg, C.B., Ferrario, F., et al. (2010) Pathologic Classification of Diabetic Nephropathy. Journal of the American Society of Nephrology, 21, 556-563. http://dx.doi.org/10.1681/ASN.2010010010

[30] Braiman-Wiksman, L., Solomonik, I., Spira, R. and Tennenbaum, T. (2007) Novel Insights into Wound Healing Sequence of Events. Toxicologic Pathology, 35, 767-779. http://dx.doi.org/10.1080/01926230701584189

[31] Lee, J.Y., Lee, F.Y., Huo, T.I., Wang, S.S., Huang, H.C., Lin, H.C., Chuang, C.L. and Lee, S.D. (2014) Diabetes Enhances the Intrahepatic Vascular Response to Endothelin-1 in Cirrhotic Rats: Association with the ET Receptor and pERK Up-Regulation. Liver International, Early View. http://dx.doi.org/10.1111/liv.12527

[32] Oliveira, P.A., Oliveira, A.M.S., Pablos, A.B., Costa, F.O., Borges Silva, G.A., dos Santos, J.N. and Cury, P.R. (2012) Influence of Hyperbaric Oxygen Therapy on Peri-Implant Bone Healing in Rats with Alloxan-Induced Diabetes. Journal of Clinical Periodontology, 39, 879-886. http://dx.doi.org/10.1111/j.1600-051X.2012.01922.x

[33] Ueno, T., Omi, T., Uchida, E., Yokota, H. and Kawana, S. (2014) Evaluation of Hyperbaric Oxygen Therapy for Chronic Wounds. Journal of Nippon Medical School, 81, 4-11. http://dx.doi.org/10.1272/jnms.81.4

[34] Stoekenbroek, R.M., Santema, T.B., Legemate, D.A., Ubbink, D.T., van den Brink, A. and Koelemay, M.J.W. (2014) Hyperbaric Oxygen for the Treatment of Diabetic Foot Ulcers: A Systematic Review. European Journal of Vascular \& Endovascular Surgery, 47, 647-655. http://dx.doi.org/10.1016/j.ejvs.2014.03.005

[35] Liu, R., Li, L., Yang, M.L., Boden, G. and Yang, G.Y. (2013) Systematic Review of the Effectiveness of Hyperbaric Oxygenation Therapy in the Management of Chronic Diabetic Foot Ulcers. Mayo Clinic Proceedings, 88, 166-175. http://dx.doi.org/10.1016/j.mayocp.2012.10.021

[36] Kranke, P., Bennett, M.H., Martyn-St James, M., Schnabel, A. and Debus, S.E. (2012) Hyperbaric Oxygen Therapy for Chronic Wounds. Cochrane Database of Systematic Reviews, 4, Article ID: CD004123. 
Scientific Research Publishing (SCIRP) is one of the largest Open Access journal publishers. It is currently publishing more than 200 open access, online, peer-reviewed journals covering a wide range of academic disciplines. SCIRP serves the worldwide academic communities and contributes to the progress and application of science with its publication.

Other selected journals from SCIRP are listed as below. Submit your manuscript to us via either submit@scirp.org or Online Submission Portal.
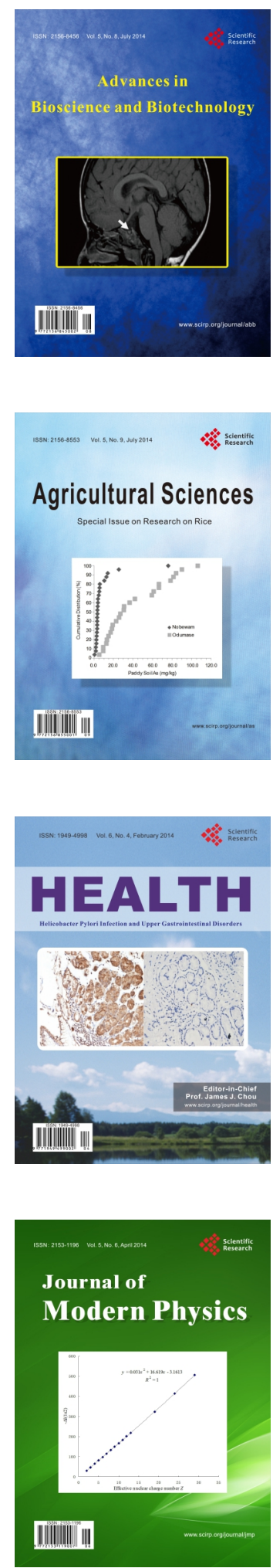
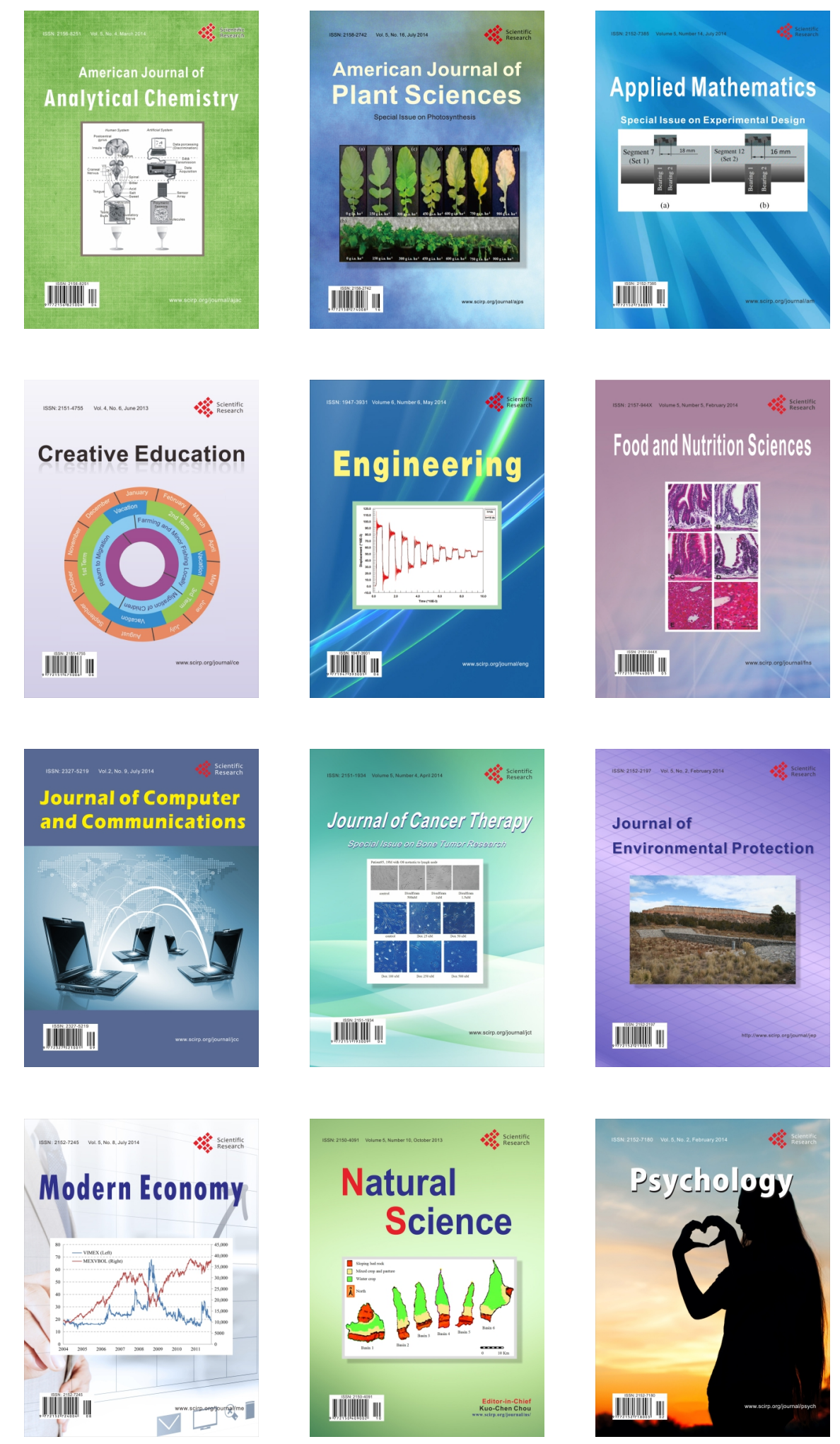